\title{
Prevalence of and public attitudes to cardiopulmonary resuscitation training in the Crimea
}

\section{Alexei Birkun, ${ }^{1}$ Yekaterina Kosova ${ }^{2}$}

${ }^{1}$ Medical Academy named after S. I. Georgievsky of V. I. Vernadsky Crimean Federal University, Simferopol, Russia (e-mail: birkunalexei@gmail.com)

${ }^{2}$ Taurida Academy of V. I. Vernadsky Crimean Federal University, Simferopol, Russia

Background and Purpose of the Study: In the former Soviet Union countries, thus far no studies have investigated the proportion of CPR-trained general public and their attitude toward CPR training. This study was aimed to investigate the occurrence of CPR training, attitudes and willingness to get trained in CPR in adult population of the Crimea.

Materials and methods: The personal interview survey was conducted from November 2017 to January 2018 in the territory of the Crimean peninsula using a quota sampling method. The sample size was calculated to be 384 (Cochran formula). The respondents were asked about previous CPR training, reasons for not attending any CPR training, willingness to learn CPR and potential motivating factors for future training. Associations of participants' characteristics with previous CPR training status and willingness to attend training were evaluated using the chi-square or the Fisher exact test, and logistic regression analysis was performed for the variables with confirmed association $(p<0.05)$.

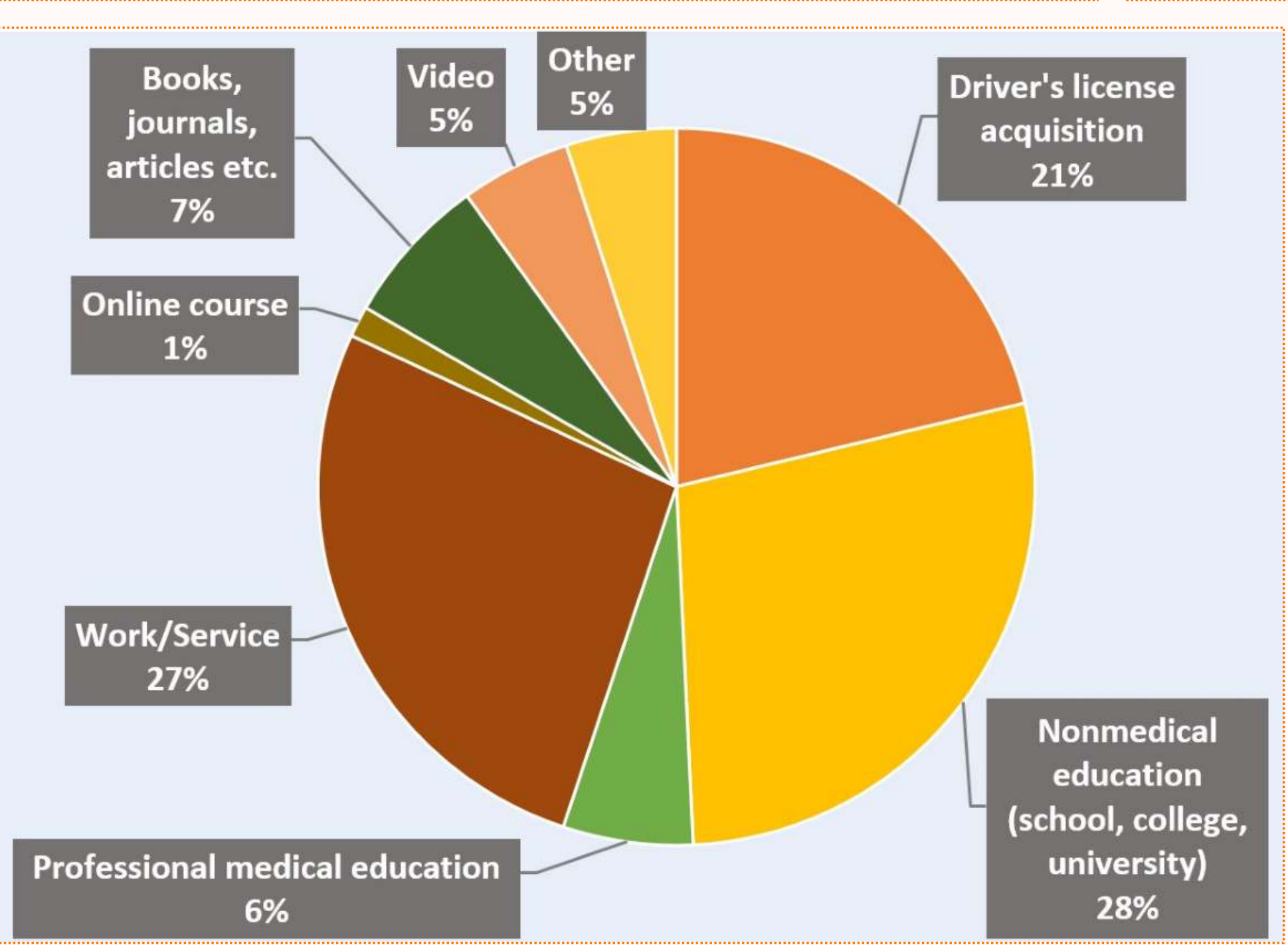

Figure 1. Distribution of prior CPR training by type.
Results: Of 384 respondents, 204 (53\%) reported previous CPR training. Among the trained, $72 \%$ received their training more than one year ago and $44 \%$ attended a single course. Trainings at workplace, when gaining education or acquiring driver's license were most prevalent (76\%) (Fig. 1). In logistic regression model, males (odds ratio [OR]: 1.7; 95\% confidence interval $[\mathrm{Cl}]: 1.1-2.6)$, those having had a university education (OR: $2.4 ; 95 \% \mathrm{Cl}$ : 1.5-3.8), employed (OR: 2.7; 95\% Cl: 1.6-4.4) and students (OR: 6.9; $95 \% \mathrm{Cl}: 2.5-19.2$ ) were found to be predictive of previous training in CPR.

Forty seven percent (180/384) of respondents had no previous CPR training. Nontrained usually never thought about the need to learn CPR or did not $\rightarrow$

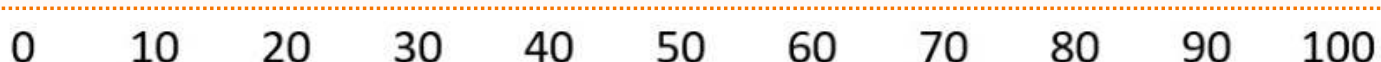

$$
\begin{aligned}
& \text { Awareness of relevance } \\
& \text { of CPR training }
\end{aligned}
$$

Potential health-related problems in relatives/friends

Free-of-charge training

High-quality training

Training in close proximity (within hometown/village) (within hometown/village) (several hours) Certificate/ nonmonetary reward
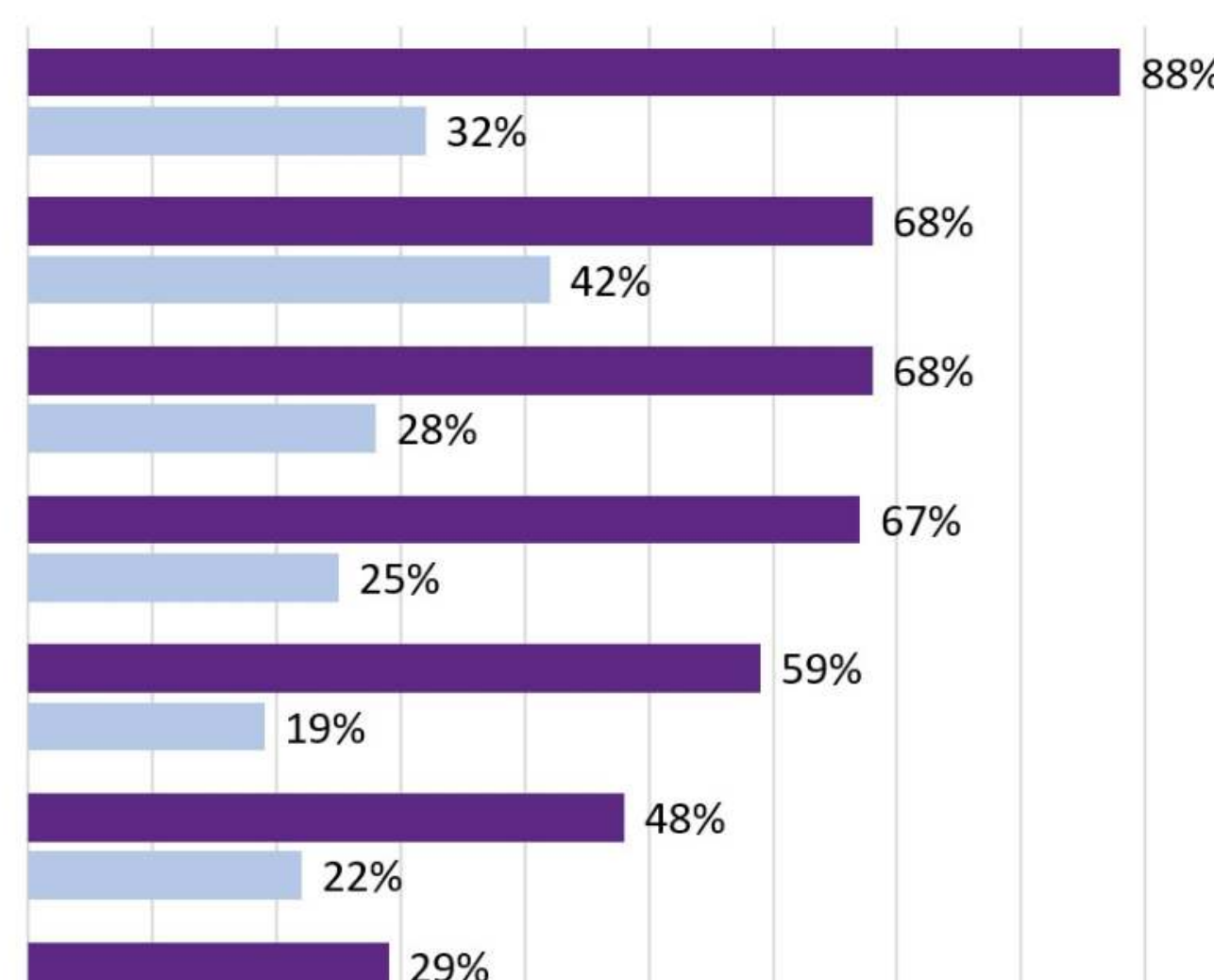

Other

$3 \%$

$2 \%$

Figure 2. Motivations for respondents to attend CPR training

Willing to attend CPR training ( $\mathrm{n}=201)$

Not willing to attend CPR training $(n=118)$

$\rightarrow$ know where to attend the training (Table)

People aged $\geq 60$, females, those with educationa level lower than high school, widowed, unemployed and retired are mostly untrained.

About $52 \%$ respondents wish to learn CPR regardless of previous training, knowledge of CPR or medical background. Females (OR: $2.3,95 \% \mathrm{Cl}$ : 1.5-3.6), persons aged $<60$ (OR: $1.9 ; 95 \% \mathrm{Cl}: 1.2$ 3.2) and nonwidowed (OR: 3.0; 95\% Cl: 1.3-6.8) are more likely to be willing to get trained. Lower interest in learning CPR was revealed in males, elderly, widowed and retired.

The distribution of motivating factors for attending CPR training among all respondents is presented in Fig. 2.
Conclusions: Having low awareness of the importance of CPR training and insufficient educational opportunities, almost a half of the Crimean lay people were never trained in CPR. Efforts should be made to increase the extent of community training and retraining, targeting the least trained population groups. Future studies are warranted to investigate the issue in other post-Soviet territories.

\begin{tabular}{|lc|}
\hline \multicolumn{1}{|c|}{ Reasons for not being trained } & $\begin{array}{c}\% \text { Nontrained } \\
\text { respondents }\end{array}$ \\
\hline Never thought about the need to go for training & $51 \%$ \\
Did not know where to attend the training & $28 \%$ \\
Always thought they have no need of CPR training & $10 \%$ \\
Reluctance to spend time & $5 \%$ \\
Reluctance to spend money & $1 \%$ \\
Other & $5 \%$ \\
\hline
\end{tabular}

Table. Reasons for not taking CPR training. 